\title{
Abstract \\ Diabetes screening in the high risk individuals: Can the Glycosylated hemoglobin test replace oral glucose tolerance test?
}

Dahanayake $\mathrm{M}^{1^{*}}$, Rathnayake $\mathrm{M}^{1}$, Bethmiarachchi $\mathrm{D}^{1}$, Jayawardhana $\mathrm{M}^{1}$, Edirisinghe $\mathrm{U}^{1}$, Weerarathna $\mathrm{T}^{1}$

${ }^{1}$ Ministry of Health, Sri Lanka

\begin{abstract}
Introduction

First degree relatives of patients with type 2 diabetes carry a high risk of pre-diabetes and diabetes. We aimed to study the diagnostic accuracy of glycosylated hemoglobin test (HbA1c) and fasting blood glucose (FBS) in screening diabetes and pre-diabetes in this category.

Methods

157 previously non-diabetic, adult, first degree relatives of diabetic patients underwent FBS, HbA1c and oral glucose tolerance test (OGTT). Sensitivity and specificity of FBS over 101 and $126 \mathrm{mg} / \mathrm{dL}$ and $\mathrm{HbA} 1 \mathrm{c}$ of $5.5 \%$ and $6.5 \%$ in detecting individuals with pre- diabetes and diabetes were determined according to the 2-hour OGTT blood glucose values of 140 and $200 \mathrm{mg} / \mathrm{dL}$ respectively.

\section{Results}

Majority (63\%) of the sample were females. Mean (SD) age, BMI were 49.9(11) years and $23.5(3.6) \mathrm{kg} / \mathrm{m} 2$. Percentages with diabetes on FBS, HbA1C and OGTT were $10.19 \%, 12.73 \%, 14 \%$ and pre-diabetes were $28.6 \%$, $45.9 \% 30.57 \%$ respectively. Sensitivity and specificity of HbA1c in detecting pre-diabetes were $83.33 \%$ and $70.64 \%$ and diabetes were $77.27 \%$ and $97.77 \%$ respectively. The corresponding figures for pre-diabetes with FBS were $60.41 \%$ and $85.32 \%$ and diabetes $68.13 \%$ and $99.25 \%$. Area under the curve of the receiver operator characteristic curves (ROC) of FBS and HbA1c with OGTT were 0.88 and 0.98 respectively.

Conclusions

In this high diabetes risk category, $\mathrm{HbA} 1 \mathrm{c}$ test detects higher percentage of patients with diabetes and pre-diabetes than FBS. Diagnostic yield of diabetes with HbA1c was superior to FBS and almost identical to OGTT. HbA1c test may replace OGTT in detecting diabetes among high risk individuals.
\end{abstract}

Key words: Type 2 diabetes mellitus; Screening in high risk individual; HbA1C

Copyright: (C) 2015 Dahanayake $\mathrm{M}$ et al. This is an open access article distributed under the Creative Commons Attribution License, which permits unrestricted use, distribution, and reproduction in any medium, provided the original work is properly cited.

\footnotetext{
* Correspondence : dahanayakemalin@yahoo.com
}

Cite this abstract as: Dahanayake M, Rathnayake M, Bethmiarachchi D, Jayawardhana M, Edirisinghe U, Weerarathna T. Diabetes screening in the high risk individuals: Can the Glycosylated hemoglobin test replace oral glucose tolerance test? . Anuradhapura Medical Journal 2015;9 (2Supp):S16.

DOI: http://dx.doi.org/10.4038/amj.v9i2Supp.7565 


\section{Submit your next Manuscript to} Anuradhapura Medical Journal

Submit your manuscript at

http://amj.sljol.info/ 